\title{
Qualidade na distribuição de sementes de milho em semeadoras em um solo cearense ${ }^{1}$
}

\author{
Quality in the distribution of corn seed by planters in a soil of the Ceará
}

\author{
Rafaela Paula Melo*, Daniel Albiero ${ }^{2}$, Leonardo Almeida Monteiro ${ }^{3}$, Fábio Henrique Souza ${ }^{3}$ e Jameson Guedes \\ Silva ${ }^{3}$
}

\begin{abstract}
RESUMO - As semeadoras são de grande importância para o sucesso no estabelecimento de uma cultura, por isso é necessário o uso correto dos equipamentos agrícolas para que haja o aumento da produtividade. Poucos são os estudos nos solos do sub-úmido cearense quanto ao uso adequado dessas máquinas, daí a importância de se realizar pesquisas nestes solos para a melhoria durante o processo de semeadura. $\mathrm{O}$ trabalho foi realizado na área experimental de Engenharia Agrícola do Centro de Ciências Agrárias da Universidade Federal do Ceará, Campus do Pici. A distribuição longitudinal foi feita em uma área com $50 \mathrm{~m}$, as velocidades avaliadas no experimento foram de $4 \mathrm{e} 7 \mathrm{~km} \mathrm{~h}^{-1}$. O delineamento experimental utilizado foi o completamente aleatório. Utilizou-se o coeficiente de simetria e curtose para verificar a normalidade dos dados, em seguida fez-se a análise de variância para médias que apresentaram normalidade, já quando os dados não se apresentavam normais utilizou-se a média móvel exponencialmente ponderada. A análise estatística foi feita através do programa SISVAR a 5\% de significância. O trabalho teve por objetivo avaliar a distribuição longitudinal de sementes de uma semeadora mecânica e uma semeadora pneumática em um solo do sub-úmido cearense.
\end{abstract}

Palavras-chave: Controle de Qualidade. Semeadora-Adubadora. Solo.

\begin{abstract}
Planters are of great importance for success in establishing a crop. The correct use of agricultural equipment is therefore necessary so that increased productivity can be obtained. Few studies have been made in soils of the sub-humid region of Ceará, of the appropriate use of these machines, hence the importance of carrying out research in these soils to improve the planting process. The experiment was conducted at the experimental area for agricultural engineering of the Centre for Agrarian Sciences, at the Federal University of Ceará, Pici Campus. Longitudinal distribution was made over an area of $50 \mathrm{~m}$, and the velocities measured in the experiment were 4 and $7 \mathrm{~km} \mathrm{~h}^{-1}$. The experimental design was completely random. The coefficient of symmetry and kurtosis were used to ensure normality of the data, then a mean variance analysis was carried out that presented normality. When the data did not present as normal, the exponentially-weighted moving average was used. Statistical analysis was performed to 5\% significance using the SISVAR software. The study had as its objective to evaluate the longitudinal distribution of seeds of both a mechanical and a pneumatic planter in a soil of the sub-humid region of Ceará.
\end{abstract}

Key words: Quality Control. Fertilizer-Seeder. Soil.

\footnotetext{
*Autor para correspondência

${ }^{1}$ Recebido para publicação em 21/09/2011; aprovado em 24/07/2012

Parte da Dissertação de Mestrado do primeiro autor do Programa de Pós-Graduação em Engenharia de Sistemas Agrícolas/UFC

${ }^{2}$ Departamento de Engenharia Agrícola, Centro de Ciência Agrárias, Universidade Federal do Ceará-UFC, Campus do Pici, Fortaleza-CE, rafaela_2708@hotmail.com

${ }_{3}^{3}$ Departamento de Engenharia Agrícola, Centro de Ciência Agrárias, Universidade Federal do Ceará-UFC, dalbiero@ufc.br, aiveca@ufc.br, fabiohenrique@agronomo.eng.br,jamesonguedes@hotmail.com
} 


\section{INTRODUÇÃO}

O solo é um fator importante para a manuntenção da produção agrícola, pois é ele que disponibiliza os nutrientes necessários para o desenvolvimento da planta, além de armazenar água e sustentar a raiz (OLIVEIRA et al., 2009). Neste enfoque, segundo o Instituto de Pesquisa e Estratégia Econômica de Ceará (2007) o estado do Ceará possui três tipos preponderantes de solos, sendo o de maior ocorrência os solos do tipo Neossolos, com cerca de 35,96\% da área do estado, já os Argissolos abrangem uma área de 24,67\% e os Luvissolos representam $16,72 \%$ da área total do estado.

Dentre os solos citados o Argissolo foi o solo utilizado no presente experimento e de acordo com Santos et al. (2006) estes solos se caracterizam por apresentarem gradiente textural, com nítida separação entre horizontes quanto à cor, estrutura e textura, são solos caracterizados como profundos a pouco profundos, moderadamente a bem drenados, com textura muito variável, mas com predomínio de textura média na superfície, e argilosa, em subsuperfície.

Existem poucos estudos nos solos cearenses quanto à avaliação da distribuição de sementes por semeadoras. Segundo Mattar (2010) a utilização de máquinas e equipamentos tem como objetivo melhorar a capacidade operacional, facilitar o trabalho do homem, melhorando assim a eficiência produtiva.

Copetti (2004) relata a importância da semeadora no processo produtivo, pois a operação de plantio é um dos principais fatores para o sucesso no estabelecimento de uma lavoura.

Neste enfoque, Mantovani, Bentavx e Rocha (1992) comentam que a utilização de máquinas e equipamentos agrícolas quando realizada de maneira correta proporciona o aumento da produtividade e permite que as atividades sejam realizadas em um tempo hábil.

Mahl et al. (2004) afirmam que a distribuição longitudinal de sementes pode ser afetada com o aumento da velocidade de deslocamento da máquina, principalmente quando se leva em consideração a velocidade periférica de deslocamento do disco dosador, pois ocorre a diminuição do número de espaçamentos aceitáveis entre sementes.

Silva e Gamero (2010) afirmam que a velocidade é um dos principais fatores que interfere na qualidade e no rendimento operacional durante a semeadura, devido a esses entraves os autores comentam que as semeadorasadubadoras vêm sofrendo modificações no intuito de melhorar a eficiência de distribuição longitudinal.

Santos et al. (2011) afirmam que o aumento da velocidade na operação de semeadura é um fator que interfere no estabelecimento de plantas, pois o aumento da velocidade influencia de forma negativa na redução da percetagem de espaçamentos aceitáveis e aumenta o número de falhas durante a semeadura. Cortez et al. (2006) afirmam que a velocidade durante as operações de semeadura podem interferir na distribuição logitudinal de sementes. Neste enfoque, Alencar, Lopes e Souza Júnior (2007) comentam que o Controle Estatístico do Processo - CEP permite reduzir a variabilidade das variáveis controladas permitindo utilizar condições operacionais que aproximem as variáveis de interesse dos seus limites de controle. Porém, Montgomery (2004) comenta que o CEPé uma ferramenta que só pode ser utilizada quando os dados apresentarem normalidade, $\mathrm{o}$ autor ainda sugere a utilização do gráfico de média móvel exponencialmente ponderada (MMEP) para a análise de processos não normais.

Fernandes, Costa e Souza (2010) comentam que o CEP auxília no controle da qualidade nas etapas do processo, principalmente nos processos repetitivos, pois visa garantir a estabilidade e a melhoria contínua do processo.

O CEP é uma ferramenta de grande utilidade para a agricultura, pois de acordo com Pauli, Milan e Salvi (2009) é muito complicado determinar todos os fatores que influem nas operações agrícolas, por isso é necessário buscar fatores que melhorem a eficiência e eficácia dessas operações, desse modo o uso de ferramentes de qualidade é necessário para garantir o desempenho adequado do processo em função dos fatores críticos.

O trabalho teve por objetivo avaliar a distribuição logitudinal de sementes de uma semeadora mecânica e uma semeadora pneumática em um solo típico do subúmido cearense.

\section{MATERIAL E MÉTODOS}

Este traballho foi realizado na área experimental de Engenharia Agrícola do Centro de Ciências Agrárias da Universidade Federal do Ceará, Campus do Pici em um Argissolo Vermelho Amarelo (EMPRESA BRASILEIRA DE PESQUISA AGROPECUÁRIA, 1999).

Na Tabela 1 são mostradas as propriedades físicas do solo da área de estudo. O solo em estudo foi classificado conforme metodologia da Empresa Brasileira de Pesquisa Agropecuária (1999), quanto à classe textural, em franco arenoso, com aproximadamente 10,60\% de argila, $82,90 \%$ de areia, $6,40 \%$ de silte.

A resistência à penetração foi realizada segundo o padrão ASAE S- 313 (ASAE 1997). O índice de cone médio da área variou de $2.500 \mathrm{kPa}$ a $3.000 \mathrm{kPa}$ e o teor de água do solo foi de $35 \%$.

O experimento foi conduzido no mês de julho de 2011. Na área utilizada demarcou-se $50 \mathrm{~m}$ para realizar a distribuição longitudinal. Foi utilizado para realização 
Tabela 1 - Propriedades físicas do solo

\begin{tabular}{cccccccccc}
\hline Solo & $\mathrm{Dp}\left(\mathrm{g} \mathrm{cm}^{-3}\right)$ & $\mathrm{Ds}\left(\mathrm{g} \mathrm{cm}^{-3}\right)$ & $\mathrm{A}(\%)$ & LL & LP & LC & Argila $(\%)$ & Areia $(\%)$ & Silte (\%) \\
\hline Franco-Arenoso & 2,71 & 1,65 & 35,00 & 13,5 & NP & NC & 10,60 & 82,90 & 6,40 \\
\hline
\end{tabular}

dos testes uma semeadora mecânica da marca Baldan de modelo PLB04X3800 com 4 linhas, com espaçamento de $0,90 \mathrm{~m}$ entre as linhas e sulcadores de discos duplos e peso aproximado de $772 \mathrm{~kg}$ e uma semeadora pneumática da marca Jumil de modelo JM2090EX.00 com 3 linhas com espaçamento de $0,90 \mathrm{~m}$ entre as linhas e sulcadores de discos duplos e peso aproximado de $1.160 \mathrm{~kg}$. As semeadoras foram reguladas para o espaçamento de $12 \mathrm{~cm}$ entre as sementes e profundidade de $5 \mathrm{~cm}$.

As velocidades avaliadas no experimento foram de 4 e $7 \mathrm{~km} \mathrm{~h}^{-1}$. Posteriormente, para a avaliação da distribuição longitudinal, os sulcos da semente foram desenterrados a cada 1 metro ao acaso. Cada repetição teve 7 agrupamentos lineares de 1 metro, distribuídos aleatoriamente na linha de plantio. A avaliação dos dados do espaçamento e profundidade foi realizada com o auxílio de uma régua.

O critério de escolha das máquinas para comparação foi função da capacidade de semeadura que atenda às necessidades da agricultura familiar do subúmido cearense. Outra característica importante para comparação foi a massa total das máquinas, pois este é um fator importante devido à patinagem que é proporcional ao peso da máquina e à tração da roda movida.

Para a avaliação das sementes duplas e falhas adotou-se a metodologia recomendada por Kurachi $e t$ al. (1989) e Albiero (2010), e as sementes quebradas foram contabilizadas visualmente.

$\mathrm{O}$ delineamento experimental utilizado foi $\mathrm{o}$ completamente aleatório. Utilizou-se o coeficiente de simetria e curtose para verificar a normalidade dos dados, em seguida fez-se a análise de variância para médias que apresentaram normalidade, já quando os dados não se apresentavam normais utilizou-se a média móvel ponderada (MMEP) para avaliar a variabilidade que ocorreu entre as médias estudadas.

Segundo Montgomery (2004) a Média Móvel Exponencialmente Ponderada (MMEP) é definida conforme a equação 1 , como:

$$
z i=\lambda \cdot \sum \frac{i-1}{0}(1-\lambda) \cdot x_{i-j}+(1-\lambda)^{i} \cdot z o
$$

onde: $z i$ é o valor da média móvel ponderada; $z o$ é a média alvo do processo; $x i$ é o valor da característica medida; $\lambda$ é o peso considerado para a média, se refere à sensibilidade em captar pequenas mudanças na média.
Os limites de controle do gráfico MMEP são dados pelas equações 2 e 3 , a seguir:

$$
\begin{aligned}
& L S C=\mu+L . \sigma \cdot \sqrt{\frac{\lambda}{(2-\lambda)}} \cdot\left[1-(1-\lambda)^{2 i}\right] \\
& L S C=\mu-L . \sigma \cdot \sqrt{\frac{\lambda}{(2-\lambda)}} \cdot\left[1-(1-\lambda)^{2 i}\right]
\end{aligned}
$$

onde: $\mu$ é a média do processo; $L$ é a largura da faixa entre a média e o limite; $\sigma$ é o desvio padrão da amostra.

Segundo Hines et al. (2006) a MMEP pode ser considerada uma média ponderada de todas as observações, os pesos decrescem geometricamente com as observações, este método atribui menos peso a observações que ocorreram há menos tempo ou menos frequentemente e sua sensibilidade depende do peso dado e do intervalo entre os limites e a média. Hunter (1989) sugeriu a escolha de peso $\lambda=0,4 \mathrm{e}$ intervalo em $3 \sigma$, o que permite detectar uma mudança do desvio padrão na média em 14,3 observações, fato comprovado por Albiero (2010) em seus estudos com distribuição longitudinal de sementes.

\section{RESULTADOS E DISCUSSÃO}

Os dados dos espaçamentos obtidos na avaliação da distribuição longitudinal de sementes para a semeadora mecânica e pneumática nas velocidades 4 e $7 \mathrm{~km} \mathrm{~h}^{-1}$ seguem na Tabela 2.

Verifica-se que para a semeadora mecânica a média obtida entre os espaçamentos estudados para a velocidade de $4 \mathrm{~km} \mathrm{~h}^{-1}$ foi de $13,4 \mathrm{~cm}$ com o desvio padrão de $10,7 \mathrm{~cm}$ e coeficiente de variação de $79,4 \%$. Já para a velocidade $7 \mathrm{~km} \mathrm{~h}^{-1}$ obteve-se a média de $11,3 \mathrm{~cm}$, o desvio padrão de $8,5 \mathrm{~cm}$ e coeficiente de variação de $75,0 \%$. Para a semeadora pneumática nas mesmas velocidades encontrou-se as médias entre espaçamento de $12,8 \mathrm{~cm}$ e $13,5 \mathrm{~cm}$, o desvio de 6,4 e 7,3 cm e coeficiente de variação de 50,1 e 53,9\% para as velocidade 4 e $7 \mathrm{~km} \mathrm{~h}^{-1}$, respectivamente. Verifica-se que para a semeadora mecânica o coeficiente de curtose na velocidade 4 e $7 \mathrm{~km} \mathrm{~h}^{-1}$ não se encontra no intervalo entre -2 e 2 , ou seja não respeitam uma distribuição normal. Como os coeficientes de curtose e simetria não apresentaram normalidade nos dados avaliados, a análise de variância é considerada ineficiente, por isso é necessário o uso de metodologias 
Tabela 2 - Estatística descritiva básica da distribuição longitudinal de sementes

\begin{tabular}{lrrrr}
\hline & \multicolumn{2}{c}{ Mecânica } & \multicolumn{2}{c}{ Pneumática } \\
\cline { 2 - 5 } & Vel. 4 km h-1 & Vel. 7 km h & Vel. $4 \mathrm{~km} \mathrm{~h}^{-1}$ & ${\text { Vel. } 7 \mathrm{~km} \mathrm{~h}^{-1}}$ \\
\hline Observações & 282,0 & 241,0 & 225,0 & 231,0 \\
Média (cm) & 13,4 & 11,3 & 12,8 & 13,5 \\
Desvio Padrão (cm) & 10,7 & 8,5 & 6,4 & 7,3 \\
Variância & 113,6 & 72,1 & 41,2 & 53,0 \\
Coeficiente de Variação (\%) & 79,4 & 75,0 & 50,1 & 53,9 \\
Mínimo & 0,0 & 0,0 & 0,0 & 0,5 \\
Máximo & 80,0 & 55,0 & 46,0 & 38,0 \\
Simetria & 2,1 & 1,4 & 0,8 & 0,6 \\
Curtose & 7,5 & 3,4 & 2,4 & 0,6 \\
\hline
\end{tabular}

adequadas para a avaliação dos dados. Já a semeadora pneumática apresentou coeficiente de curtose e simetria nas velocidades 4 e $7 \mathrm{~km} \mathrm{~h}^{-1}$ dentro no intervalo de -2 e 2 , ou seja, respeitando uma distribuição normal.

De acordo com as recomendações de Kurachi et al. (1989), para se estabelecer os limites das faixas de classes de frequência considera-se espaçamentos duplos os valores que são menores que 0,5.XREF, espaçamentos aceitáveis valores que se encontram dentro dos limites 12 a 1,5.XREF e espaçamentos falhos os valores maiores do que 1,5.XREF.

Para o experimento obtiveram-se os seguintes limites para a classificação dos espaçamentos duplos, aceitáveis e falhos: Duplo $=6 \mathrm{~cm}>12 \mathrm{~cm}>18 \mathrm{~cm}=$ Falho.

Na Tabela 3 observa-se que para a semeadora mecânica apenas 42,2 e 52,7\% dos espaçamentos apresentaram regularidade durante o processo de distribuição das sementes para a velocidade de 4 e $7 \mathrm{~km} \mathrm{~h}^{-1}$, respectivamente. Para a semeadora pneumática ocorreu apenas $64 \%$ de espaçamentos aceitáveis na velocidade de $4 \mathrm{~km} \mathrm{~h}^{-1}$ e $55,4 \%$ na velocidade de $7 \mathrm{~km} \mathrm{~h}^{-1}$, esses resultados corroboram com Balastreire et al. (1990) que em seus experimentos concluíram que a distribuição de sementes de milho foi sensível ao aumento da velocidade de deslocamento, ou seja, a distribuição de sementes apresentou-se irregular e fora dos limites aceitáveis, havendo uma maior irregularidade quando ocorria o acréscimo da velocidade de operação.

Ao comparar-se o desempenho das duas semeadoras, verifica-se que a semeadora pneumática apresentou melhor desempenho do que a semeadora mecânica, pois o número de espaçamentos não aceitáveis foi menor para a semeadora pneumática na velocidade de $4 \mathrm{~km} \mathrm{~h}^{-1}$, onde obteve-se apenas $36 \%$ de espaçamentos não aceitáveis quando comparado com a velocidade de $7 \mathrm{~km} \mathrm{~h}^{-1}$. Entretanto, esses resultados já eram esperados devido à semeadora pneumática possuir maior precisão na distribuição de sementes, porém apesar desses resultados terem apresentado melhor desempenho eles ainda são muito baixos para uma semeadora pneumática, já que segundo Mialhe (1996) estas semeadoras chegam a ter uma precisão de $90 \%$. Esses resultados corroboram com Tourino et al. (2009) que comentam que os sistemas pneumáticos podem proporcionar o estabelecimento de estandes mais uniformes e, consequentemente, maior produtividade. Em seus experimentos, os autores

Tabela 3 - Avaliação de espaçamentos duplos, falhos e sementes quebradas da semeadora mecânica e pneumática

\begin{tabular}{lrrrr}
\hline & \multicolumn{2}{c}{ Mecânica } & \multicolumn{2}{c}{ Pneumática } \\
\cline { 2 - 5 } & \multicolumn{1}{c}{ Vel. 4 $\mathrm{km} \mathrm{h}^{-1}$} & Vel. 7 km h & Vel. 4 km h & Vel. 7 km h \\
\hline Quebrada & $3(1,1 \%)$ & $1(0,4 \%)$ & $1(0,4 \%)$ & $3(1,3 \%)$ \\
Dupla & $64(22,7 \%)$ & $68(22,7 \%)$ & $33(14,7 \%)$ & $36(15,6 \%)$ \\
Falhas & $96(34,0 \%)$ & $45(18,7 \%)$ & $47(20,9 \%)$ & $64(27,7 \%)$ \\
Aceitáveis & $119(42,2 \%)$ & $127(52,7 \%)$ & $144(64,0 \%)$ & $128(55,4 \%)$ \\
\hline
\end{tabular}


concluíram que a semeadora de precisão com dosador pneumático a vácuo foi mais uniforme e proporcionou maior produtividade de grãos em relação à semeadora de dosador de tipo mecânico.

Considerando que o espaçamento esperado entre sementes era de $12 \mathrm{~cm}$, o baixo desempenho dessas semeadoras pode ser atribuido a erros de dosagem e a interferência dos elementos sulcadores que entram em contato com o solo durante o processo de semeadura pelo fato de não serem adequados aos solos do estado do Ceará, que são banstante arenosos e secos.

De acordo Montgomery (2004) e comprovado por Albiero (2010), que em seus testes com uma máquina multifuncional para agricultura familiar verificou que o seu número de amostras não foi suficiente para se obter normalidade. Por isso Albiero et al. (2012) avaliando a distribuição longitudinal entre sementes de uma semeadora de anel interno rotativo relatam que quanto maior o número de amostra mais a distribuição se aproximam de uma normal. Para análise de processo não normais Montgomery (2004) sugere a utilização do gráfico de média móvel exponencialmente ponderada (MMEP). Neste enfoque, Albiero et al. (2012) verificaram em seus testes que os dados obtidos não apresentavam distribuição normal o que inviabilizou a análise dos gráficos de controle convencionais, indicando a necessidade de utilização da metodologia da MMEP. O autor afirma que o MMEP mostrou-se uma ferramenta adequada para a avaliação da qualidade da distribuição longitudinal de sementes.

$\mathrm{Na}$ Figura 1 verifica-se que o processo apresentou pontos fora dos limites de controle para as duas velocidades avaliadas, neste caso segundo Montgomery (2004) o processo é considerado instável, porém pela teoria de Barros (2008) e confirmado por Albiero (2010) o processo pode ser considerado estável se os pontos que se encontram fora do limite de controle forem retirados, desde que mais de $95 \%$ dos pontos restantes estejam dentro do limite de controle, tal metodologia mostra-se adequada não influindo de maneira negativa, pois não mascara os dados. Observa-se que houve uma menor variabilidade na velocidade de $7 \mathrm{~km} \mathrm{~h}^{-1}$.

Na Tabela 4 encontram-se o resultado do teste F. Verifica-se que a relação entre os espaçamentos das velocidades 4 e $7 \mathrm{~km} \mathrm{~h}^{-1}$ não apresentou diferença entre as médias a 5\% de significância. Resultados semelhantes foram encontrados por Oliveira et al. (2009) que em seus testes observaram que a uniformidade de distribuição não foi afetada significativamente pela velocidade de deslocamento.

Como a semeadora pneumática apresentou normalidade para as duas velocidades estudadas utilizouse a média móvel exponencialmente ponderada (MMEP) apenas para comparar o comportamento das médias e a variabilidade dos dados com os resultados obtidos pela semeadora mecânica. Hines et al. (2006) recomenda a
Figura 1 - Gráfico da média móvel exponencialmente ponderada do espaçamento entre sementes da semeadora mecânica nas (a) velocidades $4 \mathrm{~km} \mathrm{~h}^{-1}$, (b) velocidades $7 \mathrm{~km} \mathrm{~h}^{-1}$ respectivamente

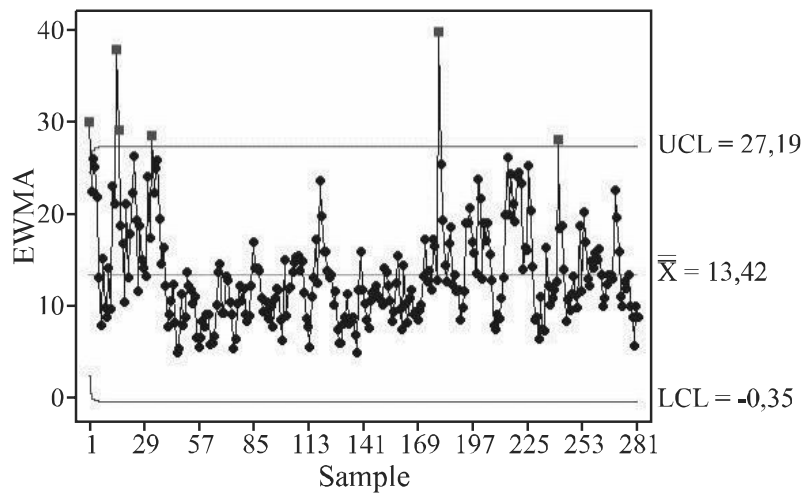

(a)

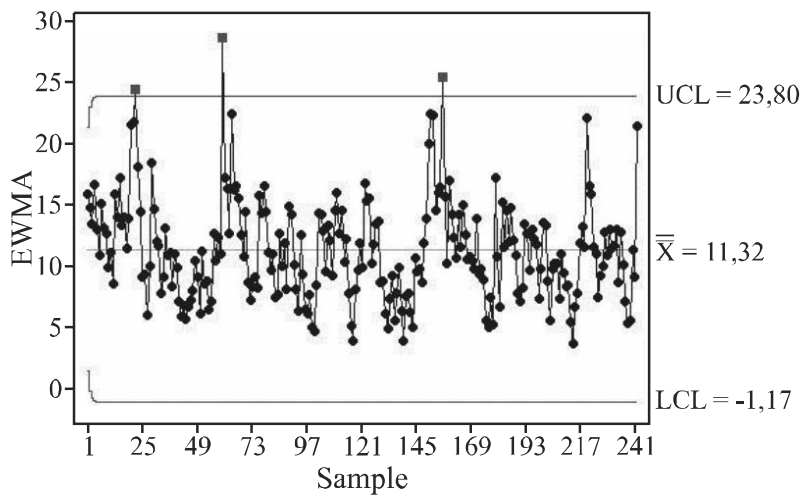

(b)

Tabela 4 - Análise de variância dos espaçamentos da velocidade 4 e $7 \mathrm{~km} \mathrm{~h}^{-1}$

\begin{tabular}{lcrccc}
\hline & GL & SQ & QM & F & P \\
\hline Fator & 1 & 53,4 & 53,4 & 1,13 & 0,288 \\
Erro & 454 & 21407,0 & 47,2 & & \\
Total & 455 & 21460,4 & & & \\
\hline
\end{tabular}

combinação dos gráficos de controle convencionais com os MMEP para identificar tanto grandes mudanças no comportamento da amostra como pequenas.

Observa-se na Figura 2 que o processo é considerado estável, porém verifica-se que ocorreu melhor desempenho para a velocidade de $4 \mathrm{~km} \mathrm{~h}^{-1}$, esses resultados concordam com Canova et al. (2007) que em suas pesquisas constataram que a menor velocidade foi a que proporcionou a distribuição de sementes mais próxima à dosagem desejada. 
Figura 2 - Gráfico da média móvel exponencialmente ponderada do espaçamento entre sementes da semeadora pneumática nas (a) velocidades $4 \mathrm{~km} \mathrm{~h}^{-1}$, (b) velocidades $7 \mathrm{~km} \mathrm{~h}^{-1}$ respectivamente

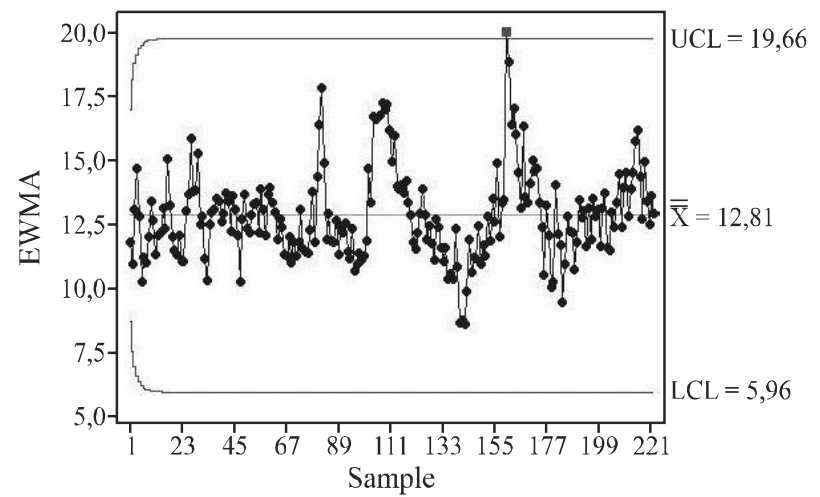

(a)

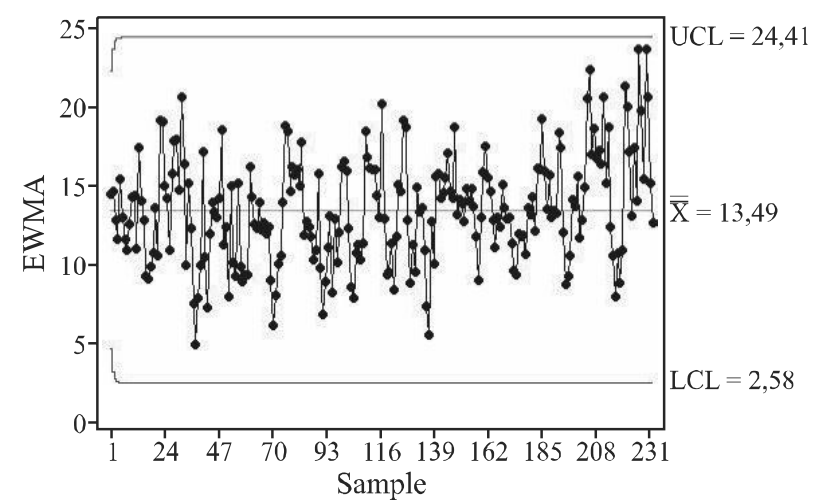

(b)

Na velocidade de $7 \mathrm{~km} \mathrm{~h}^{-1}$ nota-se que houve uma maior variabilidade, porém apesar de aparentemente a velocidade de $4 \mathrm{~km} \mathrm{~h}^{-1}$ apresentar melhor resultado através da análise de variância, pode-se concluir que não houve diferença estatítica entre as médias, ou seja, a velocidade $7 \mathrm{~km} \mathrm{~h}^{-1}$ aumentaria a capacidade de trabalho na área e o trabalho seria realizado em um tempo mais hábil.

Ao verificar-se todas as análises que foram realizadas tanto para a semeadora pneumática como para a mecânica nas velocidades 4 e $7 \mathrm{~km} \mathrm{~h}^{-1}$ é possível supor que o solo interferiu de forma direta no processo de semeadura, pois em relação às máquinas avaliadas e as metodologias utilizadas, o tipo de solo específico do sub-úmido cearense é o parâmetro menos estudado em comparação com avaliações de semeaduras em outras regiões, já que existem muitos dados em relação a semeaduras em solos com mais teores de argila, o que não é o caso de solos com alto teor de areia. $\mathrm{O}$ mesmo estava muito seco no dia dos testes, outro fator que pode ter contribuido para estes resultados é o fato de o solo ser banstante arenoso, como foi dito anteriormente, o solo estava em condições normais de semeadura para o sub-úmido cearense o que favoreceu para que ocorresse patinagem durante a operação de semeadura e consequentemente ocasionou irregularidade na distribuição das sementes. Neste enfoque, Reis et al. (2007) relatam que a eficiência do mecanismo do disco dosador está ligada com as condições de contato do rodado com o solo, principalmente quando se leva em consideração a patinagem do rodado e a velocidade de operação do conjunto trator semeadora. Vale et al. (2010) afirmam que o aumento da velocidade de deslocamento faz com que ocorra um aumento no deslizamento dos rodados da semeadora. Já Furlani et al. (2008) afirmam que as semeadoras-adubadoras possuem mecanismos dosadores que são acionados através de suas rodas motrizes que giram em função do contato com a superfície do solo, estes mecanismos são responsáveis pelo acionamento da semeadora-adubadora para que haja a correta adição das sementes e do adubo no solo. Os autores comentam que este contato com o solo é influenciado pela pressão de inflação dos pneus das semeadoras e estão diretamente relacionados com o desempenho correto da máquina.

Vários trabalhos foram realizados para comprovar a eficiência dessas semeadoras em outras regiões, porém são poucos os estudos das mesmas para as condições dos solos cearenses. Diante dos resultados obtidos observase que é necessário que seja feita uma adequação na relação transmissão da semeadora para evitar sementes com danos mecânicos e espaçamentos falhos, pois um importante fator a ser avaliado é a velocidade de deslocamento das semeadoras, já que elas vão interferir na distribuição das sementes quando se leva em consideração a velocidade tangencial dos discos dosadores. Outro fator a ser avaliado é a resistência à penetração sofrida pelos componentes rompedores, pois este tem exigido constante adaptação das máquinas. Assim, é frequente a abertura inadequada dos sulcos, aderência do solo aos componentes, profundidade de semeadura desuniforme, cobertura deficiente do sulco de semeadura e contato inadequado do solo sobre as sementes. Muitos destes problemas podem estar associados à falta de treinamento dos operadores e ao desconhecimento do potencial das máquinas. Assim, cuidados com regulagens, e retorno do solo após abertura do sulco de semeadura tornam-se importantes. $\mathrm{O}$ entendimento dos fatores que afetam a semeadura facilita a compreensão do funcionamento de uma semeadora, visando-se obter um bom desempenho. Um exemplo seria a adequação do ângulo de ataque das hastes das semeadoras para cada tipo de solo. A adequação do peso da semeadora adubadora também influencia na eficiência e qualidade de distribuição, pois se a mesma 
estiver muito leve não conseguirá vencer a resistência do solo fazendo assim que ocorra patinagem do sistema de acionamento e de distribuição.

\section{CONCLUSÕES}

1.O solo do sub-úmido cearense interferiu de forma direta no desempenho das semeadoras durante o processo de distribuição de sementes;

2.É necessário propor regulagens para essas semeadoras para as condições do solo sub-úmido cearense e assim explorar a máxima eficiência dessas semeadoras em solos cearense;

3. A MMEP se mostrou uma ferramenta adequada para avaliar a qualidade da distribuição longitudinal durante o processo de semeadura.

\section{AGRADECIMENTOS}

À Coordenação de Aperfeiçoamento de Pessoal de Nível Superior (CAPES) pela concessão da bolsa de mestrado à primeira autora desse trabalho.

\section{REFERÊNCIAS}

ALBIERO, D. Desenvolvimento e avaliação de máquina multifuncional conservacionista para a agricultura familiar. 2010. 244 f. Tese (Dourado em Engenharia Agrícola) - Universidade Estadual de Campinas, São Paulo, 2010.

ALBIERO, D. et al. Avaliação da distribuição de sementes por uma semeadora de anel interno rotativo utilizando média móvel exponencial. Revista Ciência Agronômica, v. 43, n. 01, p. 86-95, 2012

ALENCAR, J. R. B; LOPES, C. E; SOUZA JÚNIOR R. M. B. Controle Estatístico de Processo Multivariado: aplicação ao monitoramento da produção de comprimidos de captopril. Revista Brasileira de Farmácia, v. 88, n. 04, p. 200-205, 2007.

BALASTREIRE, L. A. Máquinas agrícolas. São Paulo: Manole editora, 1990. $307 \mathrm{p}$.

BARROS, F. F. A melhoria contínua no processo de plantio da cana-de-açúcar. 2008. 79 f. Dissertação (Mestrado em Máquinas Agrícolas) - ESALQ - Universidade de São Paulo, 2008.

CANOVA, R. et al. Distribuição de sementes por uma semeadoraadubadora em função de alterações no mecanismo dosador e de diferentes velocidades de deslocamento. Engenharia na Agricultura, v. 15, n. 03, p. 299-306, 2007.

COPETTI, E. Prevenir custa menos. Cultivar Máquinas, n. 27, 2004.

CORTEZ, J. W. et al. Distribuição logitudinal de sementes de soja e características físicas do solo no plantio direto. Engenharia Agrícola, v. 26, n. 02, p. 502- 510, 2006.
EMPRESA BRASILEIRA DE PESQUISA AGROPECUÁRIA. Centro Nacional de Pesquisa de Solos. Sistema brasileiro de classificação de solos. Rio de Janeiro. 1999. 412 p.

FERNANDES, A. E. S; COSTA, C. E. S; SOUZA, E. S. O. O uso de controle Estatístico de processo na gestão de qualidade. Estudo de caso: Grupo Coringa - AL. INGEPRO - Inovação, Gestão e Produção, v. 03, n. 06, p. 1-10, 2011.

FURLANI, C. E. A. et al. Semeadora-adubadora: exigências em função do preparo do solo, da pressão de inflação do pneu e da velocidade. Revista Brasileira Ciências do Solo, v. 32, p. 345-352, 2008.

HINES, W. W. et al. Probabilidade e estatística na engenharia. 4. ed. Rio de Janeiro: LTC, 2006.

HUNTER, J. S. A one point plot equivalent to the Shewart chart with western electric rules. Quality Progress, v. 02, n. 01, p. 13-19, 1989.

INSTITUTO DE PESQUISA E ESTRATÉGIA ECONÔMICA DO CEARÁ. 2007. Ceará em Mapas. Disponível em < http://www2. ipece.ce.gov.br/atlas/capitulo1/12.htm> Acesso em: 12 Set. 2011.

KURACHI, S. A. H. et al. Avaliação tecnológica de semeadoras e/ou adubadoras: tratamento de dados de ensaios e regularidade de distribuição longitudinal de sementes. Bragantia,v. 48, n. 02, p. 249-262, 1989.

MAHL, D. et al. Demanda energética e eficiência da distribuição de sementes de milho sob variação de velocidade e condição de solo. Engenharia Agrícola, v. 24, n. 01, p. 150-157, 2004.

MANTOVANI, E. C; BERTAUX, S; ROCHA, F. E. C. Avaliação da eficiência operacional de diferentes semeadoras-adubadoras de milho. Pesquisa Agropecuária Brasileira, v. 27, n. 12, p. 1579-1586, 1992.

MATTAR, D. M. P. Influência do deslizamento da roda motora de uma semeadora/adubadora de plantio direto no espaçamento longitudinal de sementes de milho. 2010. $67 \mathrm{f}$. Dissertação (Mestrado em Engenharia Agrícola) - Universidade Federal de Santa Maria, Rio Grande do Sul, 2010.

MIALHE, L. G. Máquinas agrícolas: Ensaios e certificação. Piracicaba: Fundação de estudos agrários Luiz de Queiroz, 1996.

MONTGOMERY, D. C. Introdução ao controle estatístico da qualidade. 4. ed. Rio de Janeiro: LTC, 2004.

OLIVEIRA, L. G. et al. Distribuição longitudinal de sementes de milho em função do tipo de dosador de sementes e velocidade de deslocamento. Cultivando o Saber, v. 02, n. 01, p. 140-146, 2009.

PAULI, D. G.; MILAN, M.; SALVI, J. V. Qualidade total. Cultivar Máquinas, v. 85, p 6-9, 2009.

REIS, E. F. et al. Características operacionais de uma semeadora-adubadora de plantio direto na cultura da soja (Glycine Max (L.) Merril). Revista Ciência Técnicas Agropecuárias, v. 16, n. 03, 2007.

SANTOS, A. J. et al. Análise espacial da distribuição longitudinal de sementes de milho em uma semeadora-adubadora de precisão. Bioscience Journal, v. 27, n. 01, p. 16-23, 2011. 
SANTOS, H. G. et al. Cultivo do Arroz de Terras Altas no Estado de Mato Grosso. Embrapa Arroz e feijão, n. 07. 2006. Disponível em: <http://sistemasdeproducao.cnptia.embrapa.br/ FontesHTML/Arroz/ArrozTerrasAltasMatoGrosso/index.htm>. Acesso em: 30 out. 2011.

SILVA, M. C. da; GAMERO, C. A. Qualidade da operação de semeadura de uma semeadora-adubadora de Plantio direto em função do tipo de martelete e velocidade de deslocamento. Revista Energia na Agricultura, v. 25, n. 01, p. 85-102, 2010.

TOURINO, M. C. C. et al. Semeadoras-adubadoras em semeadura convencional de soja. Ciência Rural, v. 39, n. 01, p. 245-249, 2009.

VALE, W. G. et al. Influência da velocidade de deslocamento no desempenho de uma semeadora-adubadora direta. Global Science Technology, v. 03, n. 03, p. 67-74, 2010. 